\title{
Predictive Performance of Artificial Neural Network and Multiple Linear Regression Models in Predicting Adhesive Bonding Strength of Wood
}

\author{
S. Bardak, ${ }^{\mathrm{a}, 1}$ S. Tiryaki, ${ }^{\mathrm{b}, 2}$ T. Bardak, ${ }^{\mathrm{c}, 3}$ and A. Aydin ${ }^{\mathrm{b}, 4}$ \\ ${ }^{a}$ Department of Industrial Engineering, Faculty of Engineering and Architecture, Sinop University, \\ Sinop, Turkey \\ ${ }^{\mathrm{b}}$ Department of Forest Industry Engineering, Faculty of Forestry, Karadeniz Technical University, \\ Trabzon, Turkey \\ ${ }^{c}$ Furniture and Decoration Program, Bartin Vocational School, Bartin University, Bartin, Turkey \\ 1 sbardak@sinop.edu.tr (S. Bardak) \\ 2 sebahattintiryaki@hotmail.com (S. Tiryaki) \\ 3 timucinbardak@gmail.com (T. Bardak) \\ ${ }^{4}$ aytac@ktu.edu.tr (A. Aydin)
}

УДК 539.4

\section{Искусственная нейронная сеть и модели множественной линейной регрессии для прогнозирования адгезионной прочности сцепления древесины}

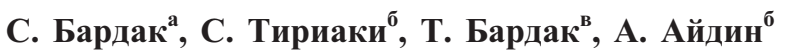 \\ ${ }^{\text {a } С и н о п с к и и ̆ ~ у н и в е р с и т е т, ~ С и н о п, ~ Т у р ц и я ~}$ \\ ${ }^{\sigma}$ Черноморский технический университет, Трабзон, Турция

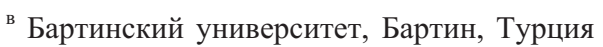

Разработаны нейронная сеть и множественные линейные регрессионные модели для оценки адгезионной прочности деревянных конструкиий с учетом их влажности и времени полной сборки элементов конструкиии до их прессования. Результать проведенных экспериментальных исследований использовали в разработанных моделях. Показано, что при увеличении влажности и времени сборки адгезионная прочность вначале растет, а затем уменьшается. С повышением времени полной сборки адгезионная прочность снижается. Сравнение расчетных результатов, полученных с помощью искусственной нейронной сети и множественных линейных регрессионных моделей, свидетельствует о преимуществе первого подхода, согласно которому коэффициент корреляциии $R^{2}=97,7 \%$, среднее отклонение составляет $3,587 \%$. Установлено, что искусственная нейронная сеть является эффективной для прогнозирования адгезионной прочности деревянных конструкций, что позволяет сократить количество трудоемких и дорогостоящих экспериментальных исследований.

Ключевые слова: искусственная нейронная сеть, прогнозирование, напряжение сцепления, множественная линейная регрессия, сравнение моделей.

Introduction. The adhesive bond of wood is one of the main connection methods used in modern load-bearing constructions [1]. The quality and durability of a wooden product primarily depends on the quality of its adhesive bonding [2]. The moisture content is among the most important factors affecting the final strength and durability of adhesive bonding [3]. The prolonged exposure to high moisture content severely reduces the 
load-bearing ability of a wood joint bonded with any adhesive. It is a fact that the penetration and cure of wood adhesives are greatly affected when the amount of moisture in wood is combined with water in adhesive [4]. The moisture content of wood at the time of bonding is also important since it influences the quality of the bond and thus the performance of the bonded product in service. A change in moisture content generally develops stresses in the adhesive joints. The magnitude of the stresses is roughly proportional to the magnitude of the change. Satisfactory adhesion between wood and adhesive is achieved with most adhesives when the wood has the moisture content ranging from 6 to $17 \%$. The lower and upper limits of the moisture content vary depending on the adhesive type and composition [5]. In addition to the moisture content, other important factors affecting adhesive bond strength of wood are the open assembly time and closed assembly time during jointing process of wood. The strength of adhesive bond of wood deteriorates if these time periods exceed the duration foreseen for adhesives [6].

The delay in obtaining the experimental results on material properties is an important problem that affects manufacturing industries [7]. Predictive model scan provides an opportunity to better evaluate the behavior of materials by carrying out a small number of complex experimental processes so that satisfactory results concerning the desired properties of materials can be obtained in a short period of time [8]. For this purpose, the two common methods are the multiple linear regression (MLR) and artificial neural network (ANN) techniques [9]. Especially, the ANN is of interest to engineers and researchers as a successful tool in modeling the behavior of materials due to its ability of describing complex and nonlinear relationships among variables by means of a small amount of data without any prior assumptions [10-12]. In addition to the ANN, the MLR has been used for modeling purposes since it is an appropriate technique for modeling when the research problem includes one dependent variable and two or more independent variables [13]. These techniques have been widely used to solve a wide variety of problems regarding the strength of materials in many engineering fields. The following literature lists some of ANN and MLR applications in predicting strength properties of various materials [9, 11, 14-18]. These modeling approaches have been also employed for predicting strength properties of wood and wood products. The applications regarding strength prediction in wood science can be listed as follows: Esteban et al. [19]; Esteban et al. [10]; Fernandez et al. [8]; Eslah et al. [20]; Tiryaki and Aydin [21]; Tiryaki et al. [22]; and Watanabe et al. [23].

As mentioned above, ANN and MLR methods have been widely employed in modeling strength of materials in many engineering fields, including wood science. However, no attempt has yet been made for predicting wood bonding strength under the conditions formulated in the present study. Therefore, one of the main goals of the present study was to predict the effect of wood moisture content, open assembly time and closed assembly time on bonding strength by ANN and MLR techniques. Another goal was to compare the predictive capabilities of these modeling techniques.

1. Materials and Methods. For this study, beech (Fagus orientalis L.) wood was chosen randomly from Artvin, Turkey. Special emphasis was made on the selection of non-deficient, knotless and defect-free beech specimens. Then the experimental specimens, which were obtained from beech wood with dimensions of $150 \times 20 \times 10 \mathrm{~mm}$, were conditioned to different amount $(8,12,16$, and $20 \%)$ of moisture content.

Polyvinylacetate (PVA) was applied to the surface of the specimens having different moisture content with an amount of adhesive of $200 \mathrm{~g} / \mathrm{m}^{2}$ by brushing at room temperature. The PVAc had density of $1.1 \mathrm{~g} / \mathrm{cm}^{3}, \mathrm{pH}=5 \ldots 6$, and viscosity value $16.0 \pm 3.0 \mathrm{MPa} \cdot \mathrm{s}$. The surfaces treated with the adhesive were kept for different open assembly time $(0,5,10$, and $15 \mathrm{~min})$ and closed assembly time (0,30, and $60 \mathrm{~min})$ prior to pressing process. The pressing pressure of $15 \mathrm{~kg} / \mathrm{cm}^{2}$ and the pressing duration of 40 min were used in bonding 
the specimens. After the bonding operation, the specimens were conditioned at a temperature of $20 \pm 2^{\circ} \mathrm{C}$ and a relative humidity of $65 \pm 5 \%$. Thus, a total of 480 specimens using four different values of moisture content, four different values of open assembly time and three different values of closed assembly time with ten replicates were prepared for bonding strength tests $(4 \times 4 \times 3 \times 10=480)$.

To determine the adhesive bond strength of the specimens, a universal testing machine with a capacity of $5000 \mathrm{~kg}$ and a loading speed of $2 \mathrm{~mm} / \mathrm{min}$ was used. Figure 1 shows the experimental design for conducting bonding strength tests of beech specimens.

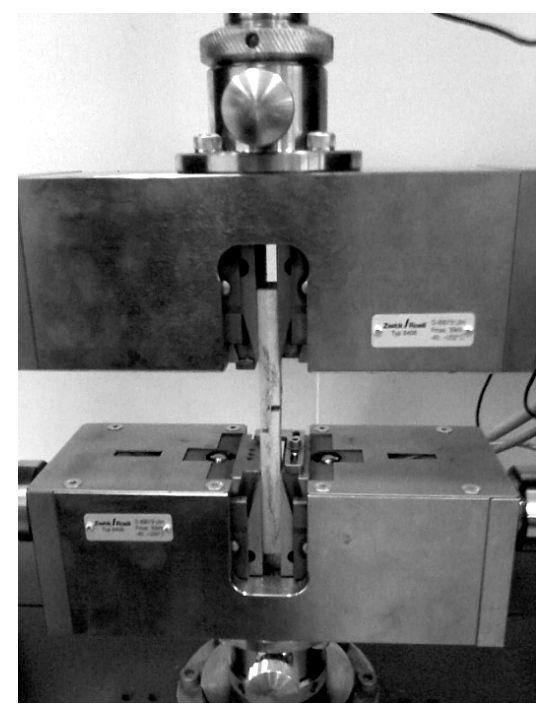

Fig. 1. Experimental design for bonding strength tests.

The loading was terminated when a break or separation on the surface of the specimens occurred. The tests were performed according to the BS EN 205 [24]. The bonding strength of specimens was derived by Eq. (1):

$$
\sigma_{y}=\frac{F_{\max }}{a b}
$$

where $\sigma_{y}$ is the bonding strength (in $\mathrm{N} / \mathrm{mm}^{2}$ ), $F_{\max }$ is the maximum load at the break point, and $a$ and $b$ are the width and length of glued face, respectively.

2. Predictive Tools and Their Applications for Bonding Strength Prediction.

2.1. Multiple Linear Regressions. Describing the functional relationship between a dependent variable and a set of independent variables is one of the classical problems in statistical analysis. The MLR analysis is a statistical technique that is very useful for these types of problems. By using this method, the linear relationship between dependent and independent variables can be successfully modeled [25]. The MLR is based on the least squares. In such a model, the best fit is achieved when the sum of squares of differences of measured and predicted outputs is minimized. In the MLR, the linear function can be formulated as Eq. (2):

$$
Y=\beta_{0}+\beta_{1} X_{1}+\ldots+\beta_{n} X_{n}+\varepsilon
$$

where $\beta_{0}$ is a constant value, $Y$ is the dependent variable, $X_{i}$ is a set of independent variables, $\beta_{i}$ - of predicted parameters, and $\varepsilon$ is the error term [26]. 
2.2. Artificial Neural Networks. ANNs are known as a massively parallel distributed processor that is able to simulate the behavior of the biological neural network [27]. They have a good capability of nonlinear mapping, which allows the network to capture the complex relationship in data structure accurately [28]. The function of ANNs resembles the human brain in two respects: (1) the network acquires the knowledge by a learning procedure, and (2) connection strengths are used to store the acquired knowledge [27].

Among many different types of ANNs, the back-propagation neural network is the most popular ANN structure for engineering problems. It is classified as a multilayer feed-forward neural network or multilayer perceptron. This means that every neuron in any layer of the ANN is connected to all neurons of the previous layer by a connection weight [29]. Figure 2 shows a typical multilayered ANN structure. Equation (3) gives the output of the MLR shown in Fig. 2 [30],

$$
Y=g\left(\theta+\sum_{j=1}^{m} v_{j}\left[\sum_{i=1}^{n} f\left(w_{i j} X_{i}+\beta_{j}\right)\right]\right),
$$

where $Y$ is the predicted value of dependent variable, $X_{i}$ is the input value of $i$ th independent variable, $w_{i j}$ is the connection or synaptic weight between the $i$ th input neuron and $j$ th hidden neuron, $\beta_{j}$ is the bias value of the $j$ th hidden neuron, $v_{j}$ is the connection weight between the $j$ th hidden neuron and output neuron, $\theta$ is the bias value for output neuron, while $g(\cdot)$ and $f(\cdot)$ are the activation functions.

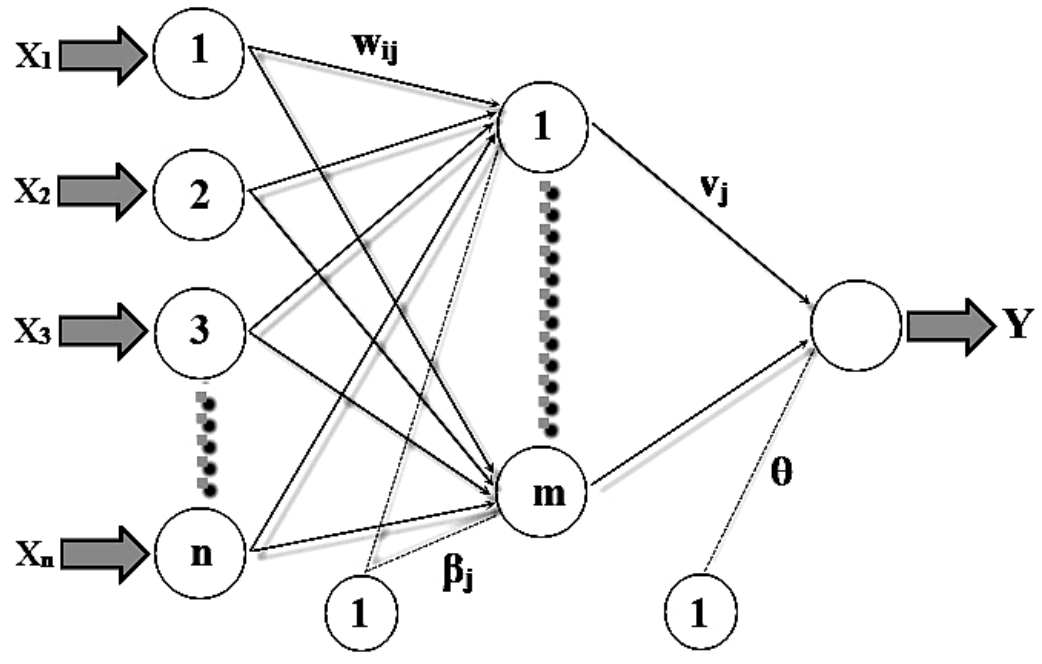

Fig. 2. A typical multi-layered ANN structure.

In Fig. 2, the input layer receives the incoming data for the ANN and delivers the data to the intermediate layer. The intermediate layer is known as the hidden layer, which transmits the information coming from the input layer to the output layer. The output layer processes the information coming from the hidden layer and thus produces the output data [31]. The number of neurons in these layers is very important in terms of the performance of the network. The number of input and output neurons is equivalent to the number of input and output variables in the MLP structure [30]. Especially, the determination of the number of hidden layers and hidden neurons is highly important factor controlling the ANN efficiency. Hidden layers and their neurons help to uncover complex relationship 
between inputs and outputs. Several researchers reported that ANN structure with a single hidden layer is generally sufficient and gives satisfactory results in solving engineering problems [32-34]. The excessive number of hidden neurons allows one to improve the memorization capability rather than generalization capability of the network. On the other hand, a too small number of hidden neurons is insufficient for the network in learning hidden relationship among variables. Thus, the optimal number of hidden layers and hidden neurons is generally found by a procedure of trial and error [34, 35].

2.3. Data Preparation for Models. In the ANN analysis for the present work, moisture content, open assembly time and closed assembly time were considered as the prime processing variables. The analysis was performed by the MATLAB Neural Network Toolbox. The experimental data were grouped into training, validation and testing data sets to model the effects of the considered variables on the bonding strength. Thirty-four data were used for training process of the ANN, while the remaining 14 data were subdivided equally for validation and testing processes of ANN. Each data point is an average of 10 measurements of the bonding strength. The training, validation and testing data sets used in the ANN are identified in Table 1. On the other hand, all of the 48 experimental data were used in developing the MLR model. The MLR analysis was performed using the SPSS 11.5 statistical software.

T a b 1 e 1

Measured and Predicted Bonding Strength Values and Their Percentage Errors

\begin{tabular}{|c|c|c|c|c|c|c|c|}
\hline \multirow{3}{*}{$\begin{array}{c}\text { Moisture } \\
\text { content } \\
(\%)\end{array}$} & \multirow{3}{*}{$\begin{array}{c}\text { Open } \\
\text { assembly } \\
\text { time (min) }\end{array}$} & \multirow{3}{*}{$\begin{array}{c}\text { Closed } \\
\text { assembly } \\
\text { time (min) }\end{array}$} & \multicolumn{5}{|c|}{ Bonding strength $\left(\mathrm{N} / \mathrm{mm}^{2}\right)$} \\
\hline & & & \multirow[t]{2}{*}{ Measured } & \multicolumn{2}{|c|}{ ANN } & \multicolumn{2}{|c|}{ MLR } \\
\hline & & & & Predicted & Error $(\%)$ & Predicted & Error $(\%)$ \\
\hline 1 & 2 & 3 & 4 & 5 & 6 & 7 & 8 \\
\hline 8 & $\mathbf{0}$ & $\mathbf{0}$ & $10.11(0.239)$ & 10.05 & 0.59 & 12.29 & -21.56 \\
\hline 8 & 0 & 30 & $9.73(0.295)$ & 9.80 & -0.72 & 11.28 & -15.93 \\
\hline 8 & 0 & 60 & $9.07(0.241)$ & 8.98 & 0.99 & 10.27 & -13.23 \\
\hline 8 & 5 & 0 & $10.25(0.193)$ & 10.24 & 0.10 & 11.93 & -16.39 \\
\hline 8 & 5 & 30 & $9.84(0.272)$ & 10.09 & -2.54 & 10.92 & -10.98 \\
\hline 8 & 5 & 60 & $9.32(0.189)$ & 9.22 & 1.07 & 9.91 & -6.33 \\
\hline 8 & 10 & $\mathbf{0}$ & $9.66(0.280)$ & 9.43 & 2.38 & 11.58 & -19.88 \\
\hline 8 & 10 & 30 & $9.41(0.185)$ & 9.23 & 1.91 & 10.56 & -12.22 \\
\hline 8 & 10 & 60 & $8.06(0.175)$ & 8.25 & -2.36 & 9.55 & -18.49 \\
\hline 8 & 15 & 0 & $9.58(0.243)$ & 9.01 & 5.95 & 11.22 & -17.12 \\
\hline 8 & 15 & 30 & $8.99(0.387)$ & 8.94 & 0.56 & 10.21 & -13.57 \\
\hline 8 & 15 & 60 & $7.78(0.249)$ & 8.04 & -3.34 & 9.19 & -18.12 \\
\hline 12 & 0 & 0 & $13.49(0.551)$ & 12.59 & 6.67 & 11.25 & 16.60 \\
\hline 12 & 0 & 30 & $11.27(0.167)$ & 11.42 & -1.33 & 10.24 & 9.14 \\
\hline 12 & 0 & 60 & $10.52(0.244)$ & 10.54 & -0.19 & 9.23 & 12.26 \\
\hline 12 & 5 & $\mathbf{0}$ & $14.90(0.376)$ & 13.86 & 6.98 & 10.90 & 26.85 \\
\hline 12 & 5 & 30 & $11.85(0.371)$ & 11.76 & 0.76 & 9.88 & 16.62 \\
\hline 12 & 5 & 60 & $10.80(0.216)$ & 10.76 & 0.37 & 8.87 & 17.87 \\
\hline 12 & 10 & 0 & $12.18(0.329)$ & 12.14 & 0.33 & 10.54 & 13.46 \\
\hline 12 & 10 & 30 & $11.13(0.162)$ & 10.99 & 1.26 & 9.53 & 14.38 \\
\hline 12 & 10 & 60 & $9.73(0.384)$ & 9.78 & -0.51 & 8.51 & 12.54 \\
\hline 12 & 15 & 0 & $11.65(0.160)$ & 11.69 & -0.34 & 10.18 & 12.62 \\
\hline 12 & 15 & 30 & $10.64(0.161)$ & 10.72 & -0.75 & 9.17 & 13.82 \\
\hline 12 & 15 & 60 & $9.49(0.376)$ & 9.46 & 0.32 & 8.16 & 14.01 \\
\hline
\end{tabular}


Continued Table 1

\begin{tabular}{||c|c|c|c|c|c|c|c||}
\hline 1 & 2 & 3 & 4 & 5 & 6 & 7 & 8 \\
\hline 16 & 0 & 0 & $10.07(0.207)$ & 9.89 & 1.79 & 10.22 & -1.49 \\
$\mathbf{1 6}$ & $\mathbf{0}$ & $\mathbf{3 0}$ & $\mathbf{9 . 7 2}(\mathbf{0 . 1 1 2})$ & $\mathbf{9 . 5 1}$ & $\mathbf{2 . 1 6}$ & 9.20 & 5.35 \\
16 & 0 & 60 & $9.00(0.124)$ & 8.90 & 1.11 & 8.19 & 9.00 \\
16 & 5 & 0 & $10.19(0.170)$ & 10.43 & -2.36 & 9.86 & 3.24 \\
16 & 5 & 30 & $9.79(0.275)$ & 9.98 & -1.94 & 8.85 & 9.60 \\
16 & 5 & 60 & $9.23(0.214)$ & 9.27 & -0.43 & 7.84 & 15.06 \\
$\mathbf{1 6}$ & $\mathbf{1 0}$ & $\mathbf{0}$ & $\mathbf{1 0 . 0 1}(\mathbf{0 . 1 4 8})$ & $\mathbf{9 . 9 6}$ & $\mathbf{0 . 5 0}$ & 9.50 & 5.09 \\
16 & 10 & 30 & $9.53(0.120)$ & 9.35 & 1.89 & 8.49 & 10.91 \\
16 & 10 & 60 & $8.43(0.361)$ & 8.47 & -0.47 & 7.48 & 11.27 \\
16 & 15 & 0 & $9.71(0.262)$ & 9.64 & 0.72 & 9.14 & 5.87 \\
$\mathbf{1 6}$ & $\mathbf{1 5}$ & $\mathbf{3 0}$ & $\mathbf{9 . 1 3}(\mathbf{0 . 3 7 6})$ & $\mathbf{9 . 0 8}$ & $\mathbf{0 . 5 5}$ & 8.13 & 10.95 \\
16 & 15 & 60 & $8.21(0.249)$ & 8.22 & -0.12 & 7.12 & 13.28 \\
20 & 0 & 0 & $8.02(0.209)$ & 8.12 & -1.25 & 9.18 & -14.46 \\
$\mathbf{2 0}$ & $\mathbf{0}$ & $\mathbf{3 0}$ & $\mathbf{6 . 8 0}(\mathbf{0 . 1 9 6})$ & 7.05 & -3.68 & 8.17 & -20.15 \\
$\mathbf{2 0}$ & $\mathbf{0}$ & $\mathbf{6 0}$ & $\mathbf{5 . 4 3}(\mathbf{0 . 3 4 8})$ & $\mathbf{5 . 5 9}$ & $\mathbf{- 2 . 9 5}$ & 7.15 & -31.68 \\
20 & 5 & 0 & $8.66(0.325)$ & 8.38 & 3.23 & 8.82 & -1.85 \\
20 & 5 & 30 & $7.21(0.106)$ & 7.23 & -0.28 & 7.81 & -8.32 \\
20 & 5 & 60 & $6.03(0.300)$ & 6.07 & -0.66 & 6.80 & -12.77 \\
20 & 10 & 0 & $7.49(0.192)$ & 7.68 & -2.54 & 8.46 & -12.95 \\
20 & 10 & 30 & $6.36(0.213)$ & 6.36 & 0 & 7.45 & -17.14 \\
20 & 10 & 60 & $5.10(0.169)$ & 5.02 & 1.57 & 6.44 & -26.27 \\
20 & 15 & 0 & $7.03(0.207)$ & 7.01 & 0.28 & 8.11 & -15.36 \\
$\mathbf{2 0}$ & $\mathbf{1 5}$ & $\mathbf{3 0}$ & $\mathbf{5 . 9 6}(\mathbf{0 . 1 5 6})$ & $\mathbf{5 . 7 3}$ & $\mathbf{3 . 8 6}$ & 7.09 & -18.96 \\
20 & 15 & 60 & $4.42(0.384)$ & 4.44 & -0.45 & 6.08 & -37.56 \\
\hline
\end{tabular}

Notes. Values in bold italic are testing data, values in bold are validation data, other values are training data. Values in parenthesis are standard deviations.

2.4. Training of Neural Network. The training is an important step of the model construction process. It is aimed at determining the optimal values of connection weights. In other words, it implies minimizing the error between the network output and actual output [36]. To achieve this goal, the network is trained using the training data. The training algorithm chosen for the present study was the Levenberg-Marquardt algorithm. In addition, the learning rule chosen was back-propagation algorithm. To assess the generalization ability of the network, the trained models were then tested with the testing data. The models providing the best prediction values were selected for predicting the adhesive bond strength of wood.

2.5. Neural Network Structure. Figure 3 depicts the proposed optimal network structure for predicting the bonding strength.

The proposed model contains one input layer, one hidden layer and one output layer. Determining the number of neurons in input and output layers is easy. In a prediction problem based on cause and effect relationship, their number is equal to the number of input variables (moisture content, open assembly time and closed assembly time) and output variable (bonding strength), respectively. On the other hand, as mentioned previously, determining the number of hidden neurons is relatively complicated [34]. Hence, a heuristic approach was applied for deriving the optimum number of hidden neurons. This approach involves designing of different network structures using various network configurations and training parameters until the optimal model for the problem under consideration is 


\section{HIDDEN LAYER}

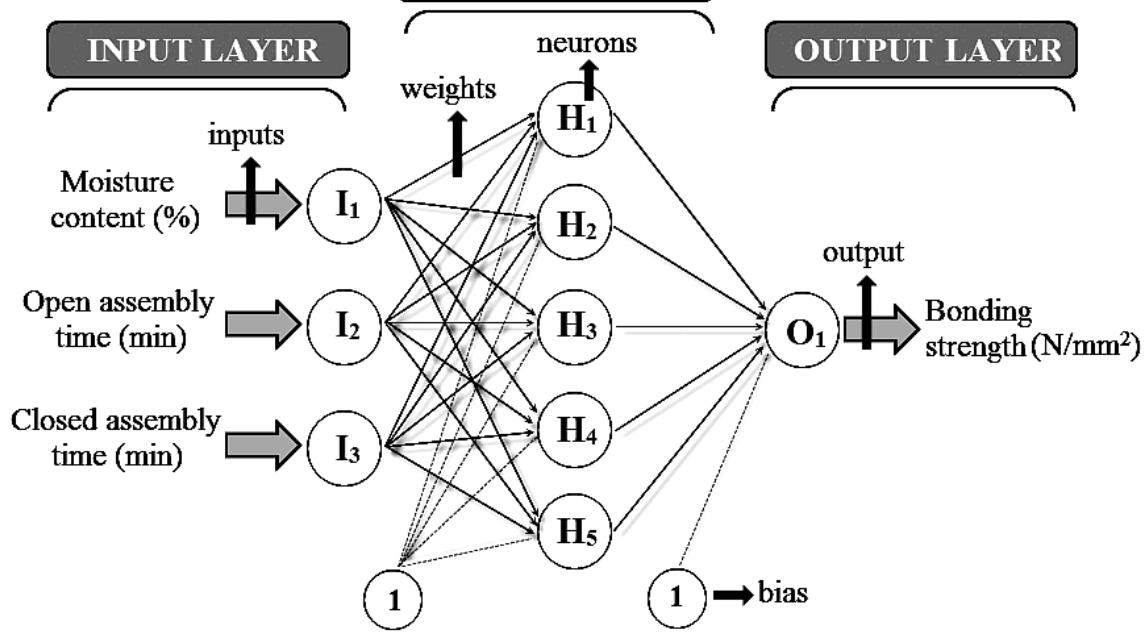

Fig. 3. The proposed optimal network structure for predicting bonding strength.

obtained [37]. Consequently, the 3-5-1 neuron configuration was found to be the best configuration of the network, as shown in Fig. 3, since it gave an excellent prediction performance.

2.6. Evaluation of Predictive Performance of Models. In evaluating the performance of the established models, the mean absolute percentage error (MAPE), the root mean square error (RMSE) and correlation coefficient $\left(R^{2}\right)$ were used, which were calculated using Eqs. (4)-(6):

$$
\begin{aligned}
\text { MAPE } & =\frac{1}{N}\left(\sum_{i=1}^{N}\left[\left|\frac{t_{i}-t d_{i}}{t_{i}}\right|\right]\right) \cdot 100, \\
\text { RMSE } & =\sqrt{\frac{1}{N} \sum_{i=1}^{N}\left(t_{i}-t d_{i}\right)^{2},} \\
R^{2} & =1-\frac{\sum_{i=1}^{N}\left(t_{i}-t d_{i}\right)^{2}}{\sum_{i=1}^{N}\left(t_{i}-\bar{t}\right)^{2}},
\end{aligned}
$$

where $t_{i}$ are the measured values, $t d_{i}$ are the predicted values, $N$ is the total number of specimens, and $\bar{t}$ is the average of predicted values.

\section{Results and Discussion.}

3.1. Experimental Results. Table 1 gives the experimental (measured) and predicted by the ANN outputs of bonding strength for training, validation and testing data sets.

To investigate the effects of moisture content, adhesive open assembly time and closed assembly time on bonding strength of the specimens, an analysis of variance was performed, and the results of the analysis were presented in Table 2. The results showed that the effects of these variables on the bonding strength were statistically highly significant $(P \leq 0.01)$. 
$\mathrm{T}$ a b 1 e 2

Results of Analysis of Variance Indicating the Effects of the Moisture Content (A), Open Assembly Time (B) and Closed Assembly Time (C) on the Bonding Strength

\begin{tabular}{||l|c|c|c|c|c||}
\hline \multicolumn{1}{|c|}{ Source } & $\begin{array}{c}\text { Sum } \\
\text { of squares }\end{array}$ & $\begin{array}{c}\text { Degrees } \\
\text { of freedom }\end{array}$ & $\begin{array}{c}\text { Mean } \\
\text { square }\end{array}$ & $F$ value & Probability \\
\hline Moisture content (A) & 736.929 & 3 & 245.643 & 3519.765 & $* * *$ \\
\hline Open assembly time (B) & 57.870 & 3 & 19.290 & 276.402 & $* * *$ \\
\hline Closed assembly time (C) & 164.000 & 2 & 82.000 & 1174.960 & $* * *$ \\
\hline A*B & 7.767 & 9 & 0.863 & 12.366 & $* * *$ \\
\hline A*C & 24.145 & 6 & 4.024 & 57.662 & $* * *$ \\
\hline B*C & 2.665 & 6 & 0.444 & 6.363 & $* * *$ \\
\hline A*B*C & 9.191 & 18 & 0.511 & 7.316 & $* * *$ \\
\hline Error & 13.400 & 192 & 0.070 & & \\
\hline Total & $21,269.076$ & 240 & & & $*$ \\
\hline
\end{tabular}

*** Significant at $P \leq 0.001$ level.

Furthermore, the Duncan mean comparison test was employed to compare the average values of bonding strength based on the process variables. Thus, one could determine which level of related variable was different from the other levels. According to the above test results, the average values of the bonding strength depending on moisture content and open assembly time fall into four different homogeneity groups, while the closed assembly time corresponded to three different homogeneity groups. Table 3 presents the results of the Duncan grouping test.

$\mathrm{T}$ a b 1 e 3

Homogeneity Groups of Bonding Strength Depending on the Process Variables

\begin{tabular}{||c|c|c|c||}
\hline \multirow{2}{*}{ Variables } & \multirow{2}{*}{ Value } & \multicolumn{2}{|c||}{ Bonding strength $\left(\mathrm{N} / \mathrm{mm}^{2}\right)$} \\
\cline { 2 - 4 } & & Average & Homogeneity group \\
\hline Moisture content (\%) & 8 & 9.32 & $\mathrm{~A}$ \\
& 12 & 11.47 & $\mathrm{~B}$ \\
& 16 & 9.42 & $\mathrm{C}$ \\
& 20 & 6.54 & $\mathrm{D}$ \\
\hline Open assembly time (min) & 0 & 9.43 & $\mathrm{~A}$ \\
& 5 & 9.84 & $\mathrm{~B}$ \\
& 10 & 8.92 & $\mathrm{C}$ \\
& 15 & 8.55 & $\mathrm{D}$ \\
\hline \multirow{2}{*}{ Closed assembly time (min) } & 0 & 10.19 & $\mathrm{~A}$ \\
& 30 & 9.21 & $\mathrm{~B}$ \\
& 60 & 8.16 & $\mathrm{C}$ \\
\hline
\end{tabular}

It is shown that the wood moisture content strongly affected the strength of the bond between wood and adhesive. According to the average values of process variables, an increase in moisture content from 8 to $12 \%$ gives a higher bonding strength. The increased 
moisture content above $12 \%$ leads to reduced bonding strength. This may be due to a decrease in the penetration of adhesive to wood with increasing moisture content. Several researchers reported that most of the strength properties of wood vary inversely with the moisture content of the wood below the fiber saturation point [38-40]. It was also claimed that some strength properties may decrease again at low moisture content after reaching the maximum value [39].

In terms of the open assembly time, it was determined that the bonding strength increased first and then dropped for open assembly time of 10 to $15 \mathrm{~min}$. In other words, the optimal bonding strength was obtained for open assembly time of $5 \mathrm{~min}$. The reason behind the bonding strength reduction with the increased open assembly time may be due to the curing of the adhesive applied to the surface of the adherents before bonding process is completed. Moreover, the strength of the adhesive bond is possibly reduced due to insufficient penetration of the adhesive into wood for a very low duration of open assembly time (0 min). In an earlier study, Minelga and Norvydas [6] reported that the increased open assembly time generally resulted in the wood bonding strength reduction.

For the effects of the closed assembly time on the bonding strength, in the present investigation it was observed that the bonding strength decreased with increasing the closed assembly time. The highest value of bonding strength was obtained for wood specimens with $0 \mathrm{~min}$ of the closed assembly time as compared to those of 30 and $60 \mathrm{~min}$. It was reported that the quality of the bond significantly deteriorates when the closed assembly time exceeds the one recommended for the adhesive [6]. This leads to the wood bonding strength reduction. Thus, it can be reported that the results of the present study are generally compatible with those of earlier studies.

3.2. Predictive Ability of the ANN and MLR Methods. In the present study, the ANN and MLR models were applied to predict the effects of moisture content, open assembly time and closed assembly time on the bonding strength. The ANN model produced highly satisfactory results as compared to the MLR model. As seen from Table 1, in the most cases, the neural network outputs are very close to the measured outputs, while the MLR outputs are less satisfactory. In other words, the prediction of bonding strength by means of the ANN in the present study was achieved with a low level of the error.

As mentioned before, such criteria as MAPE, RMSE, and $R^{2}$ were used for assessing the model fit and prediction accuracy. The obtained results are given in Table 4.

\section{T A B L E 4}

Performance Evaluation Criteria Considered for Predicting Bonding Strength

\begin{tabular}{|c|c|c|c|c|}
\hline \multirow{2}{*}{ Model } & \multirow{2}{*}{ Data sets } & \multicolumn{3}{|c|}{ Performance evaluation criteria } \\
\cline { 3 - 5 } & & MAPE & RMSE & $R^{2}$ \\
\hline \multirow{2}{*}{ ANN } & Training & 0.972 & 0.113 & 0.996 \\
& Validation & 2.707 & 0.427 & 0.995 \\
& Testing & 3.587 & 0.439 & 0.977 \\
\hline \multirow{2}{*}{ MLR } & All data & 14.220 & 1.410 & 0.524 \\
\hline
\end{tabular}

As shown in Table 4, the RMSE value drawn from the ANN was 0.439 for testing data set in predicting the bonding strength under given conditions. The corresponding value of MLR model was 1.410. On the other hand, the MAPE criterion is considered to be the decisive factor, since it is expressed in easy generic percentage term [13]. According to this, the MAPE was found as $3.587 \%$ for the testing phase of the ANN, while the MAPE value produced by the MLR was $14.220 \%$. According to Lewis [41], typical MAPE values for 
performance evaluation are categorized as follows: MAPE $\leq 10 \%$ corresponds to a high accuracy prediction, $10 \leq \mathrm{MAPE} \leq 20 \%$ - a good prediction, $20 \leq \mathrm{MAPE} \leq 50 \%-\mathrm{a}$ reasonable prediction, while $\mathrm{MAPE} \geq 50 \%$ means inaccurate prediction. In this regard, the ANN exhibited a high accuracy, while the MLR gave a good accuracy in predicting the bonding strength. In other words, the ANN yielded more satisfactory results as compared to the MLR.

The goodness-of-fit of the ANN and MLR models was evaluated by means of the regression coefficient $R^{2}$. Figure 4 gives a graphical presentation of the fit between the predicted and measured outputs of bonding strength for these models.

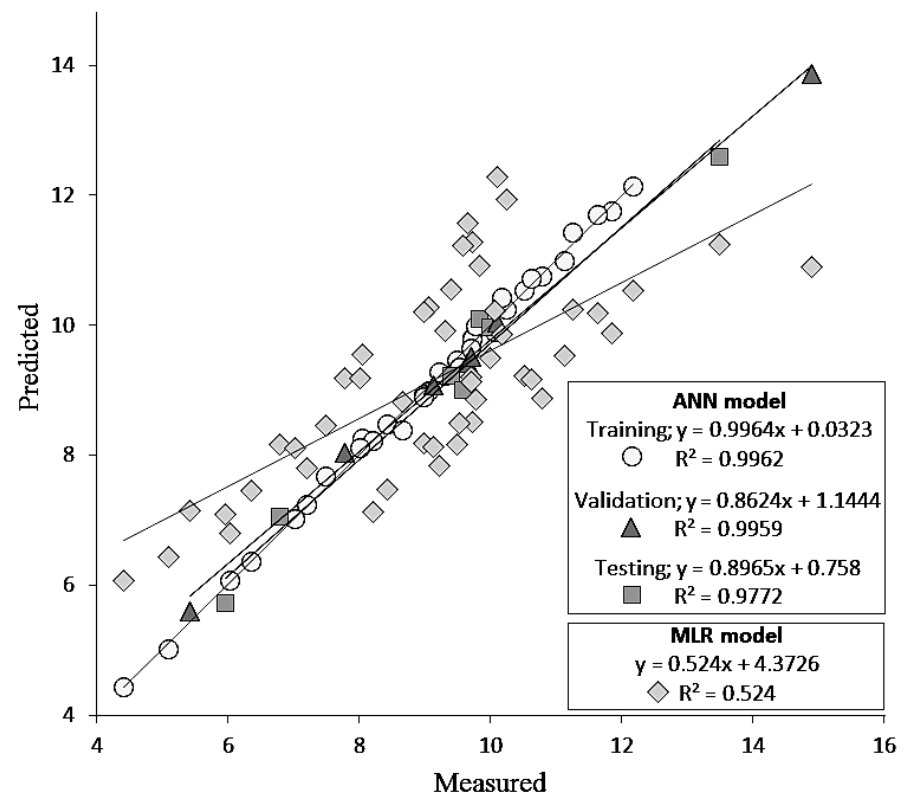

Fig. 4. Relationship between the bonding strength measured and predicted results of the ANN and MLR models.

According to Fig. 4, it can be seen that $R^{2}$ values were $0.996,0.995$, and 0.977 for training, validation and testing data sets in predicting the bonding strength of the specimens, respectively. The $R^{2}$ results of the ANN indicated that the established model coincides with at least $97 \%$ of the measured data of bonding strength. It is also possible to observe from Fig. 4 that the MLR has yielded a low $R^{2}$ value of 0.524 , which indicates that $52.4 \%$ of the variations for the bonding strength can be described by the MLR model. As a result, analysis of the data depicterd in Fig. 4 demonstrates that the bonding strength prediction by the ANN ensures a better accuracy, in comparison to the MLR. It was reported that if a model gives $R^{2}$ over 0.90 , there is an excellent correlation between measured and predicted outputs. In other words, such a model exhibits an excellent performance. On the other hand, the value of $R^{2}$ in the range of 0.82 to 0.90 generally indicates a good performance, whereas the value of $R^{2}$ below 0.82 means a relatively poor performance $[42,43]$. In this regard, the high values of $R^{2}$ for the ANN in the current study mean an excellent agreement between the measured and predicted outputs of bonding strength and increase the reliability of the ANN. Regarding the MLR, it can be reported that this model exhibited a relatively poor prediction performance. Figure 4 clearly demonstrates that the performance of the ANN is better than that of the MLR, based on the values of $R^{2}$. 


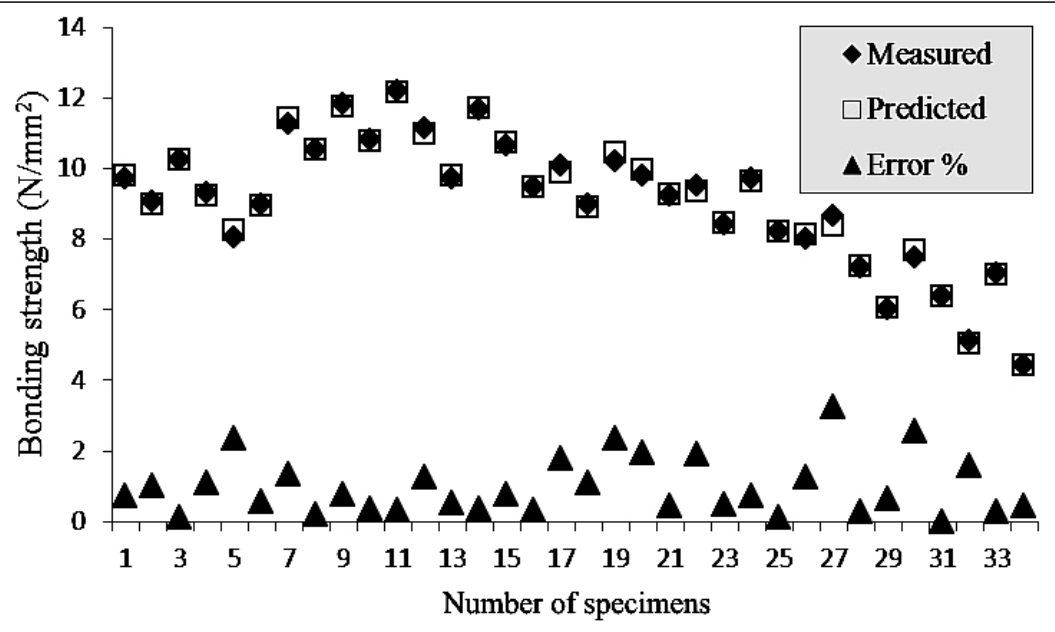

a

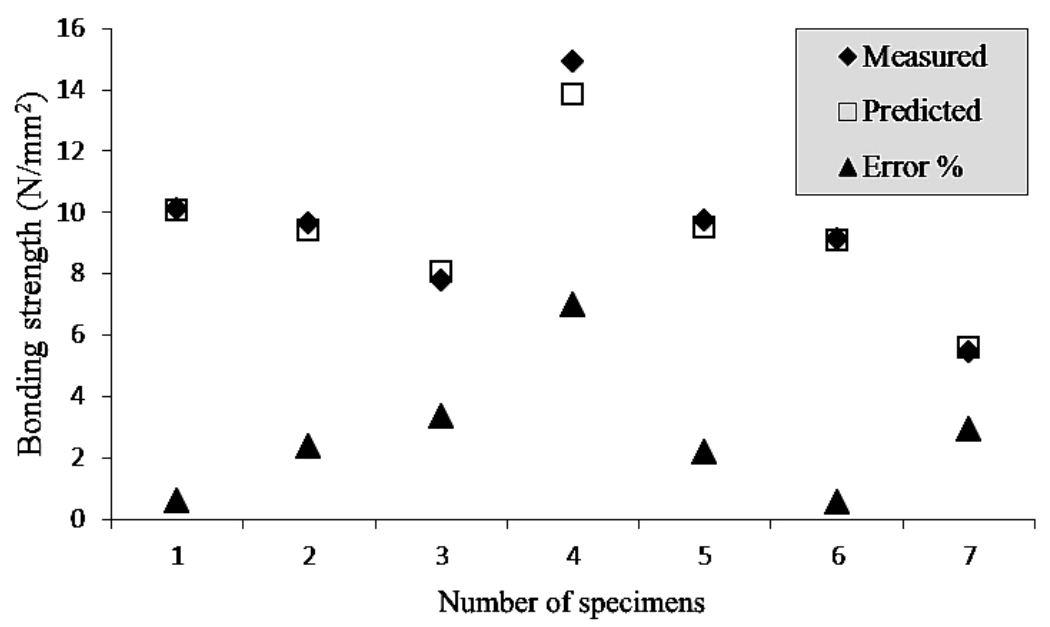

b

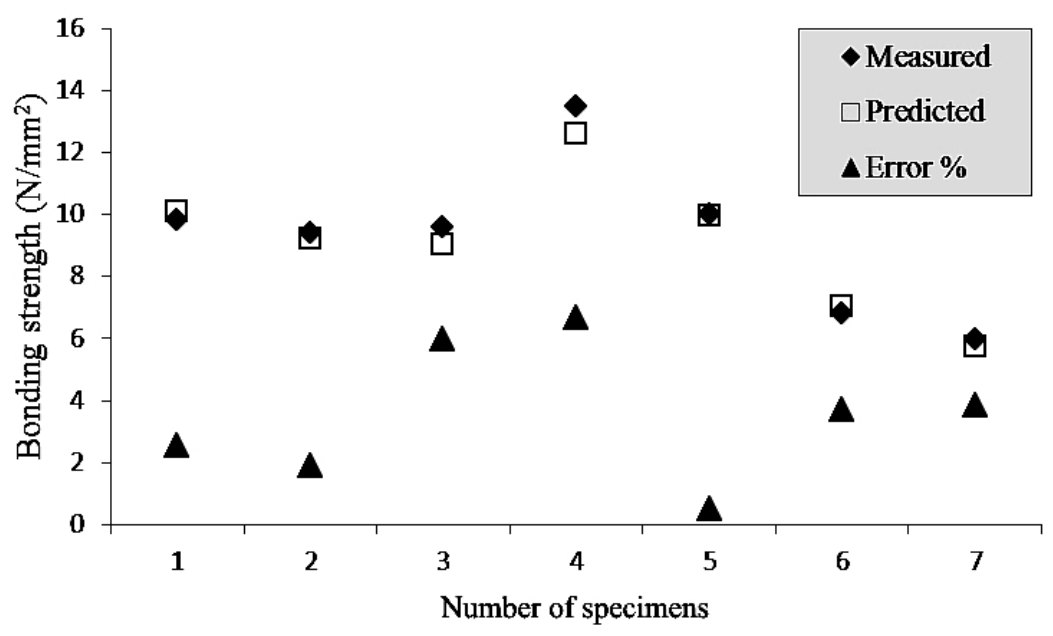

c

Fig. 5. Comparison of experimental and predicted results of bonding strength for training data (a), validation data (b), and testing data (c). 
The results of performance evaluation of such criteria as MAPE, RMSE, and $R^{2}$ have proven that ANNs have a better predictive performance than the conventional statistical methods such as the MLR. These results support the superiority of ANN over the MLR. Previous investigations have reported similar results [8, 21-23]. Indeed, the main reason behind the success of the ANN is its ability for capturing complex, hidden and nonlinear relationships among variables by means of a small amount of data without any prior assumptions [44]. Moreover, the MLR technique generally requires some assumptions such as normality, linearity, etc., unlike the ANN [45]. For the present study, it is possible to conclude that the relationship between the bonding strength and process variables may be complex, and thus it may not be captured by MLR. As stated before, ANNs are capable of accurate mapping of complex or nonlinear relationship between the variables [28]. Therefore, findings of the present study are reasonable and compatible with those of earlier investigations.

The following MLR equation [Eq. (7)] was also obtained by applying the MLR analysis to the measured data on the bonding strength:

$$
Y=14.366-0.259 X_{1}-0.072 X_{2}-0.034 X_{3} .
$$

In Eq. (7), $Y$ is a dependent variable (bonding strength) and $X_{i}$ are independent variables (moisture content, open assembly time, and closed assembly time, respectively).

Comparison of measured and predicted values of the bonding strength by the ANN model for training, validation and testing data sets is illustrated by Fig. 5. Figure 6 also gives a comparison of the ANN, MLR, and measured results for all data on the bonding strength.

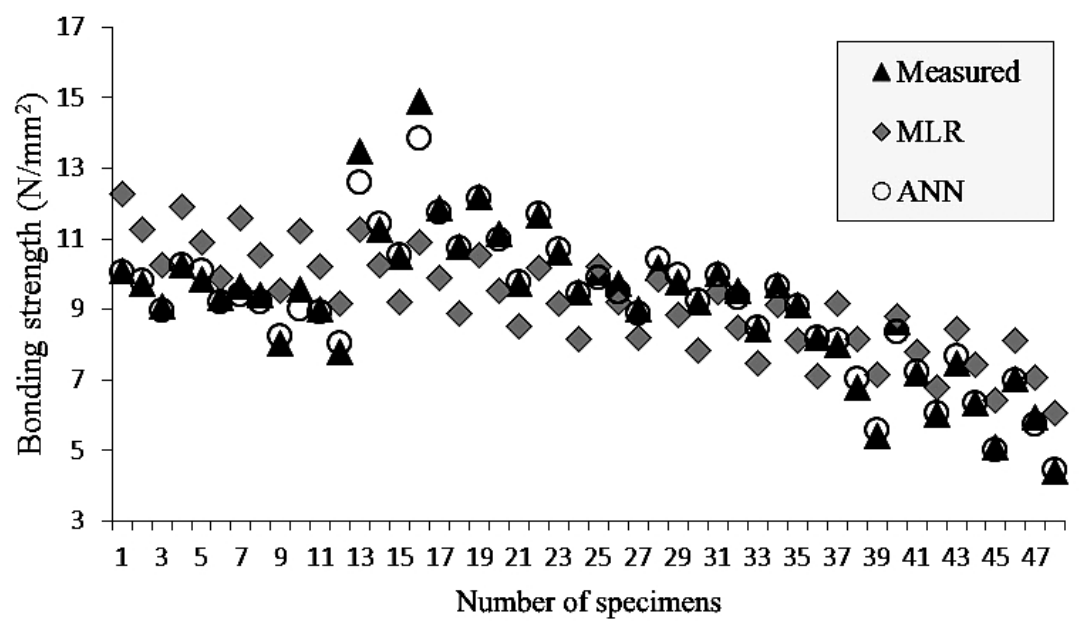

Fig. 6. Comparison of the measured, ANN, and MLR results.

From Fig. 5, it is possible to see that the ANN results for training, validation and testing data sets have a high similarity with the measured bonding strength values. It can be also observed from Fig. 6 that the ANN prediction results show very low deviations from the measured values, as compared to the MLR results. These results clearly indicate that the ANN modeling can be successfully employed for predicting bonding strength of the specimens under given conditions when its training is properly performed. In light of these findings, it is possible to conclude that the ANN exhibits a better predictive performance, as compared to the MLR and, thus, the ANN model can be effectively applied to the bonding strength prediction. 
Conclusions. In this study, the capability of ANN and MLP models for predicting bonding strength of wood have been investigated. In order to evaluate the predictive performance of the models, the $R^{2}$, MAPE, and RMSE criteria have been used.

The experimental results show that moisture content strongly affects the bonding strength. Bonding strength generally increased with reducing the moisture content of wood, except for $8 \%$ of moisture content. The optimal value of bonding strength was obtained at $12 \%$ of moisture content. For open assembly time, bonding strength first increased and then decreased with the increased open assembly time. Also, the increased closed assembly time leads to the bonding strength reduction. By considering these observations, a considerable improvement in the strength of the bond between wood and adhesive can be achieved.

The results of the ANN model were compared with those of the MLR and revealed the superiority of the ANN over the MLR in predicting the bonding strength. In other words, the proposed ANN model has exhibited a higher prediction performance than the MLR model based on the performance criteria such as MAPE and $R^{2}$. In the testing phase of the ANN, the MAPE and $R^{2}$ equalled to $3.587 \%$ and $97.7 \%$, respectively. The corresponding values of MLR were 14.22 and $52.4 \%$, respectively. Therefore, it can be concluded that the ANN successfully models the effects of different process variables on wood bonding strength, in contrast to the MLR. Based on the present study findings, it can be also concluded that ANN approach offers a novel and alternative method for predicting the bonding strength with a smaller number of experimental tests.

\section{Р ез юм е}

Розроблено нейронні мережі і множинні лінійні регресійні моделі для оцінки адгезійної міцності дерев'яних конструкцій з урахуванням їх вологості та часу повного складання елементів конструкції до їх пресування. Результати проведених експериментальних досліджень використовували в розроблених моделях. Показано, що зі збільшенням вологості і часу складання адгезійна міцність спочатку зростає, а потім знижується. Зі збільшенням часу повного складання адгезійна міцність знижується. Порівняння розрахункових результатів, отриманих за допомогою штучної нейронної мережі і множинних лінійних регресивних моделей, свідчить про переваги першого методу, згідно з яким коефіцієнт кореляції $R^{2}=97,7 \%$, середнє відхилення складає $3,587 \%$. Установлено, що штучна нейронна мережа $є$ ефективною для прогнозування адгезійної міцності дерев'яних конструкцій, що дозволяє скоротити кількість трудомістких і дорогих експериментальних досліджень.

1. P. Hass, O. Kläusler, S. Schlegel, and P. Niemz, "Effects of mechanical and chemical surface preparation on adhesively bonded wooden joints," Int. J. Adhes. Adhes., 51, 95-102 (2014).

2. I. Horman, S. Hajdarević, S. Martinović, and N. Vukas, "Stiffness and strength analysis of corner joint," Tech. Technol. Educ. Ma., 5, 48-53 (2010).

3. A. Sonmez, M. Budakci, and M. Bayram, "Effect of wood moisture content on adhesion of varnish coatings," Sci. Res. Essays, 4, No. 12, 1432-1437 (2009).

4. C. B. Vick, Adhesive Bonding of Wood Materials, in: Wood Handbook: Wood as an Engineering Material, Ch. 9, FPL-GTR-113, Madison, WI (1999), pp. 9.1-9.24.

5. M. L. Selbo, Adhesive Bonding of Wood, Technical Bulletin No. 1512, USDA, Washington, DC (1975). 
6. D. Minelga and V. Norvydas, "Properties of halogensilane modified poly(vinyl acetate) dispersion," Mater. Sci. (Medžiagotyra), 11, No. 2, 146-149 (2005).

7. D. F. Cook, C. T. Ragsdale, and R. L. Major, "Combining a neural network with a genetic algorithm for process parameter optimization," Eng. Appl. Artif. Intel., 13, No. 4, 391-396 (2000).

8. F. G. Fernandez, P. de Palacios, L. G. Esteban, et al., "Prediction of MOR and MOE of structural plywood board using an artificial neural network and comparison with a multivariate regression model," Compos. Part B - Eng., 43, No. 8, 3528-3533 (2012).

9. B. Khalilmoghadam, M. Afyuni, K. C. Abbaspour, et al., "Estimation of surface shear strength in Zagros region of Iran - A comparison of artificial neural networks and multiple-linear regression models," Geoderma, 153, 29-36 (2009).

10. L. G. Esteban, F. G. Fernandez, and P. de Palacios, "Prediction of plywood bonding quality using an artificial neural network," Holzforschung, 65, 209-214 (2011).

11. U. Atici, "Prediction of the strength of mineral admixture concrete using multivariable regression analysis and an artificial neural network," Expert Syst. Appl., 38, 96099618 (2011).

12. T. A. Choudhury, N. Hosseinzadeh, and C. C. Berndt, "Improving the generalization ability of an artificial neural network in predicting in-flight particle characteristics of an atmospheric plasma spray process," J. Therm. Spray Technol., 21, No. 5, 935-949 (2012).

13. G. Aydin, I. Karakurt, and C. Hamzacebi, "Artificial neural network and regression models for performance prediction of abrasive waterjet in rock cutting," Int. J. Adv. Manuf. Tech., 75, 1321-1330 (2014).

14. V. A. Boguslaev, A. G. Sakhno, V. K. Yatsenko, and N. V. Gonchar, "Fatigue strength prediction of KhN73MBTYu-VD alloy compressor disks," Strength Mater., 31, No. 4, 424-428 (1999).

15. M. M. F. Zain, and S. M. Abd, "Multiple regression model for compressive strength prediction of high performance concrete," J. Appl. Sci., 9, No. 1, 155-160 (2009).

16. B. B. Adhikari, and H. Mutsuyoshi, "Prediction of shear strength of steel fiber RC beams using neural networks," Constr. Build. Mater., 20, 801-811 (2006).

17. V. K. Singh, D. Singh, and T. N. Singh, "Prediction of strength properties of some schistose rocks from petrographic properties using artificial neural networks," Int. J. Rock Mech. Min., 38, 269-284 (2001).

18. A. T. Seyhan, G. Tayfur, M. Karakurt, and M. Tanoglu, "Artificial neural network (ANN) prediction of compressive strength of VARTM processed polymer composites," Comp. Mater. Sci., 34, 99-105 (2005).

19. L. G. Esteban, F. G. Fernandez, and P. de Palacios, "MOE prediction in Abies pinsapo Boiss. timber: Application of an artificial neural network using non-destructive testing," Comput. Struct., 87, 1360-1365 (2009).

20. F. Eslah, A. A. Enayati, M. Tajvidi, and M. M. Faezipour, "Regression models for the prediction of poplar particleboard properties based on urea formaldehyde resin content and board density," J. Agric. Sci. Technol., 14, 1321-1329 (2012).

21. S. Tiryaki and A. Aydin, "An artificial neural network model for predicting compression strength of heat treated woods and comparison with a multiple linear regression model," Constr. Build. Mater., 62, 102-108 (2014).

22. S. Tiryaki, S. Ozsahin, and I. Yildirim, "Comparison of artificial neural network and multiple linear regression models to predict optimum bonding strength of heat treated woods," Int. J. Adhes. Adhes., 55, 29-36 (2014). 
23. K. Watanabe, H. Korai, Y. Matsushita, and T. Hayashi, "Predicting internal bond strength of particleboard under outdoor exposure based on climate data: comparison of multiple linear regression and artificial neural network," J. Wood Sci., 61, 151-158 (2015).

24. BS EN 205: 1991. Test Methods for Wood Adhesives for Non-Structural Applications. Determination of Tensile Bonding Strength of Lap Joints, BSI, London (1991).

25. H. Tabari, A. Sabziparvar, and M. Ahmadi, "Comparison of artificial neural network and multivariate linear regression methods for estimation of daily soil temperature in an arid region," Meteorol. Atmos. Phys., 110, 135-142 (2011).

26. S. Kalayci, SPSS Practical Multivariate Statistical Techniques, Asil Publishing Distribution, Ankara (2010).

27. S. Haykin, Neural Networks: A Comprehensive Foundation, Macmillan, New York (1994).

28. J. Li, Y. K. Jia, N. Y. Shen, et al., "Effect of grinding conditions of a TC4 titanium alloy on its residual surface stresses," Strength Mater., 47, No. 1, 2-11 (2015).

29. V. T. Troshchenko, L. A. Khamaza, V. A. Apostolyuk, and Yu. N. Babich, "Strainlife curves of steels and methods for determining the curve parameters. Part 2. Methods based on the use of artificial neural networks," Strength Mater., 43, No. 1, 1-14 (2011).

30. S. Tiryaki and C. Hamzaçebi, "Predicting modulus of rupture (MOR) and modulus of elasticity (MOE) of heat treated woods by artificial neural networks," Measurement, 49, 266-274 (2014).

31. T. Varol, A. Canakci, and S. Ozsahin, "Prediction of the influence of processing parameters on synthesis of Al2024-B4C composite powders in a planetary mill using an artificial neural network," Sci. Eng. Compos. Mater., 21, No. 3, 411-420 (2014).

32. G. Cybenko, "Approximation by superposition of a sigmoidal function," Math. Control Signal, 2, 303-314 (1989).

33. K. Hornik, M. Stinchcombe, and H. White, "Multilayer feedforward networks are universal approximators," Neural Networks, 2, 359-366 (1989).

34. C. Hamzacebi, D. Akay, and F. Kutay, "Comparison of direct and iterative artificial neural network forecast approaches in multi-periodic time series forecasting," Expert Syst. Appl., 36, 3839-3844 (2009).

35. I. Kaastra and M. Boyd, "Designing a neural network for forecasting financial and economic time series," Neurocomputing, 10, 215-236 (1996).

36. H. R. Maier, A. Jain, G. C. Dandy, and K. P. Sudheer, "Methods used for the development of neural networks for the prediction of water resource variables in river systems: current status and future directions," Environ. Model. Softw., 25, 891-909 (2010).

37. R. Baratti, B. Cannas, A. Fanni, et al., "River flow forecast for reservoir management through neural networks," Neurocomputing, 55, No. 3, 421-437 (2003).

38. A. J. Panshin and C. de Zeeuw, Textbook of Wood Technology, McGraw-Hill, New York (1980).

39. E. Güntekin, and T. Y. Aydin, "Effects of moisture content on some mechanical properties of Turkish Red pine (Pinus brutia Ten.),"in: Proc. of the International Caucasian Forestry Symposium (Oct. 24-26, 2013, Artvin, Turkey), pp. 878-883.

40. M. Nocetti, M. Brunetti, and M. Bacher, "Effect of moisture content on the flexural properties and dynamic modulus of elasticity of dimension chestnut timber," Eur. J. Wood Prod., 73, 51-60 (2015). 
41. C. D. Lewis, International and Business Forecasting Methods, Butterworths, London (1982).

42. P. Williams and K. Norris (Eds.), Near-Infrared Technology: in the Agricultural and Food Industries, 2nd edn, American Association of Cereal Chemists, St. Paul, MN (2001), p. 143.

43. J. H. Cheng and D. W. Sun, "Recent applications of spectroscopic and hyperspectral imaging techniques with chemometric analysis for rapid inspection of microbial spoilage in muscle foods," Compr. Rev. Food Sci. F., 14, 478-490 (2015).

44. A. T. C. Goh and W. G. Zhang, "An improvement to MLR model for predicting liquefaction induced lateral spread using multivariate adaptive regression splines," Eng. Geol., 170, 1-10 (2014).

45. G. K. Uyanik and N. Güler, "A study on multiple linear regression analysis," Proc. Soc. Behav. Sci., 106, 234-240 (2013).

Received 13. 08. 2015 